\title{
The Process of Support by Nursing Professionals for Families Having a Member with Borderline Personality Disorder
}

\author{
Yasuyo Nishimoto*, Naohiro Hohashi \\ Division of Family Health Care Nursing, Department of Nursing, Graduate School of Health Sciences, Kobe \\ University, Hyogo, Japan \\ Email: *yasuyo-n@panda.kobe-u.ac.jp
}

Received 8 January 2016; accepted 19 January 2016; published 22 January 2016

Copyright (C) 2016 by authors and Scientific Research Publishing Inc.

This work is licensed under the Creative Commons Attribution International License (CC BY). http://creativecommons.org/licenses/by/4.0/

(c) (i) Open Access

\section{Abstract}

The purpose of this study was to explore the process of family support provided by nurses to families with a borderline personality disorder (BPD) patient. Semi-structured interviews were conducted with 16 nurses who had provided care to BPD patients. Data obtained from the interviews were qualitatively analyzed using a modified grounded theory approach. As an overall core category of family support processes practiced by nurses for families with BPD patients, family support practiced without awareness that the nurses were supporting families was extracted. Through this process, nurses held perceptions that were premises for family support, which were formed through their individual nursing experiences and perspectives. Nurses also had diverse perceptions concerning the image of families. Through the integration of perceptions that were premises for family support and perceptions of an image of the family, nurses underwent a process of "determination and ambivalence about the need for family support." Then, nurses provided "family support practice" when they acknowledged the need for family support. During the "family support practice," nurses had difficulties in providing family support. When family support was not successfully provided, nurses provided "family support practice with seeking more effective ways through trial and error." For cases in which nurses did not acknowledge the need for intervention, they intentionally chose "not to provide family support." Furthermore, during the "family support practice," nurses had contradictory perspectives of family support. Such family support processes ultimately led to an awareness of the same family support required for the future. Family support was provided with "family support practice" and "family support practice with seeking more effective ways through trial and error." In some cases, however, the process ended in "not to provide family support intentionally." Experiences and perspectives in providing family support are important factors in carrying out future family support. Developing the positive implications of these factors and reducing psychological strain on nurses may ensure smooth implementation of family

\footnotetext{
"Corresponding author.
} 
support. Thus, nurses need to recognize that they are supporting the family, which is identified as a core category.

\title{
Keywords
}

\author{
Family Nursing, Process of Family Support, Borderline Personality Disorder (BPD), Modified \\ Grounded Theory Approach (M-GTA)
}

\section{Introduction}

Borderline personality disorder (BPD) presents various signs in interpersonal relationships, self-image, and emotions such as instability and impulsivity. It usually appears in early adulthood and is diagnosed in various circumstances [1]. In order to be diagnosed with BPD, at least five of the nine criteria must be present: 1) frantic efforts to avoid real or imagined abandonment; 2) a pattern of unstable and intense interpersonal relationships characterized by alternating between extremes of idealization and devaluation; 3) identity disturbance: markedly and persistently unstable self-image or sense of self; 4) impulsivity in at least two areas that are potentially self-damaging; 5) recurrent suicidal behavior, gestures, or threats, or self-mutilating behavior; 6) affective instability due to a marked reactivity of mood; 7) chronic feelings of emptiness; 8) inappropriate, intense anger or difficulty controlling anger and 9) transient, stress-related paranoid ideation or severe dissociative symptoms. Intense or uncontrollable emotion is one of the symptoms, and patients typically show repeated dependence and aggressive behavior toward others [1]. The patients might also suffer from chronic feelings of emptiness and disconnectedness, and when they find themselves unable to handle such emotions, they often engage in such behavior as self-inflicted injury or heavy drinking. Furthermore, many harbor deep anxieties of abandonment often allude to suicide as a means of retaining relationships with others, which is manifested in such selfdestructive impulsive actions as wrist-cutting and overdosing. Other types of negative behavior take the forms of overspending or sexual aberrations.

In most cases, difficulties that the family faces due to problematic behaviors of the patient serve as the impetus for visiting a medical facility, rather than difficulties that the patient feels himself. Previous studies have found that BPD patients perceive their caregivers' attitudes as lacking in affection, over-protective, controlling, and lenient [2] [3]. In such families, family dysfunction may occur with difficulties in role performance both within and outside the family. Because the patient affects the family and vice versa, and in some cases treatment should involve a family component [4], this disorder requires support for the entire family unit.

The lifetime prevalence of BPD is 5.9\% [5] and the frequency of BPD in the general population is known to be $0.7 \%$ to $2.0 \%$ [6]. However, the prevalence of BPD in psychiatric patients is much higher with $20 \%$ to $60 \%$ among inpatients and $11 \%$ to $34 \%$ among outpatients, making encounters with BPD patients and their families fairly common among psychiatric practitioners. Although this disorder had been referred to as "borderline cases" until the 1980s, BPD was currently recognized as a disorder and guidelines [7] for treatment were developed in 2008. However, no established standard treatment method has yet to be developed, and in general patients do not receive treatment from mental health professionals [8]. Given such background, multidisciplinary team care has been shown to be effective, through use of a combination of treatment methods in accordance with patients' conditions.

Likewise, the methods of support for families with BPD patients have not been established. In addition, many nurses with experiences in caring for BPD patients have encountered difficulties in providing caring for such patients [9]. Thus, developing a support model for BPD patients and their families is an urgent issue, and investigation of nursing support as is currently being provided is required. Few existing studies, however, have reported on families with BPD patients, and none of these has focused on family support.

Understanding the current family support and nursing process that may influence the future direction of family support may lead to identifying issues in nursing practice for families with BPD patients, improve the quality of care, and reduce the sense of difficulty that nurses encounter in their daily practice. Therefore, the purpose of this study is to investigate qualitatively the processes of family support that nurses provide to families with BPD patients. 


\section{Methods}

\subsection{Definition of Terms}

Family is operationally defined as "a family including the patient," and the process of family nursing is operationally defined as "a process of family support including nurses' perceptions and thoughts about the families including patients with BPD, practice of family support, and future direction of support.”

\subsection{Study Design}

A modified grounded theory approach (M-GTA) developed by Kinoshita [10] was used in this qualitative functional study. The M-GTA is based on several basic characteristics including intentionality in theory generation, the principle of grounded-on-data, empirical evidence, meaningful interpretation, and application for validation. These characteristics were adopted from the original grounded theory approach (GTA) [11]. In M-GTA, data coding method was further specified to facilitate application. The analysis process was also modified for others to understand, and improved by means of emphasizing the views of researchers. The fundamental element of M-GTA is research about social interaction in which humans interact each other, thereby making it appropriate for studies in the field of human services. Furthermore, it is appropriate for research in which studied phenomena are concerned with the feature of process of phenomena. The phenomena explored by the current study occurred in nursing practice in the fields of human service, and consisted of interactions between nurses and families with BPD patients. Therefore, M-GTA was used in this study to investigate a series of such processes.

\subsection{Participants}

Participants of this study were 16 nurses who had experienced interactions with families of BPD patients in the course of their work as inclusion criteria. They were purposefully and continuously selected based on the content of previously conducted interviews. In other words, participants who could provide information relevant to this study were selected and investigated, and recruitment of the participants was ongoing by means of the theoretical sampling method.

\subsection{Data Collection Methods}

The settings of this study were two psychiatric hospitals and one home-visit nursing station that provided medical care for BPD patients. Information packages, including purpose and summary of the study, ethical considerations such as voluntary nature of participation and preservation of anonymity, were distributed through each facility's staff. Semi-structured interviews were conducted with nurses who agreed to participate, between October and November 2014. The interviews were conducted individually in a location where the privacy was protected or according to preferences of the subjects. Although duration of the interviews was in principle set for 60 minutes, the actual duration was flexible according to the subjects' circumstances. The contents of the interviews were about issues related to family members of BPD patients and features of such families from the view point of the nurse. The nurses were also asked concerning the experiences and feelings of BPD patients in providing family support, and how they perceived the features of families with them.

As the interviews were semi-structured, the subjects spoke freely within the general framework of the interviews. The interviews were recorded using an IC recorder with the consent of the subjects. In cases when the subjects declined to be recorded by the IC recorder, notes were taken instead with their consent, and a detailed field notes were taken within the interview day. A verbatim record was created based on the IC recorder audio data and notes.

\subsection{Data Analysis}

Data were analyzed qualitatively and inductively using M-GTA. Based on M-GTA, subjects of analysis were "nurses who had experiences providing family support to families with BPD patients," and a theme of analysis was "how the subjects perceived the families and provided support for them, what the nurses experienced through the support practice, and what consequences about the future family support they reached." While compiling the obtained data and the theme of analysis, we looked at certain points, and generated concepts by means of interpreting why we looked at them and what were the implications for the subjects. Constant comparative 
analysis and theoretical sampling were repeated, and analysis and data collection were continued until theoretical saturation was reached.

Relationships between generated concepts were investigated and classified into categories, and a diagram was created to explain the phenomena that were the subjects of analysis. To ensure credibility and validity of data, the subjects' thoughts or ideas, and that the subjects agreed with the validity of the researchers' interpretation, were confirmed by the researchers during each interview. Twelve researchers with expertise in the field of family nursing were involved in the analysis process, with supervision undertaken.

\subsection{Ethical Considerations}

This study was conducted with the approval of the university's ethics committee. Participants were informed about this study by oral explanation and written information. The provided information included overview of the study; arbitrary property of the investigation; and maintaining of anonymity. The participants were also informed that non-participation or withdrawal from participation would not cause any disadvantages, and that study content would not affect any of their assessments in their workplaces. Informed consent was obtained with signature of the participants.

\section{Results}

\subsection{Participants}

A single interview was conducted with each nurse $(n=16)$ who had an experience of interacting with families of BPD patients in their nursing practice. The interview duration ranged from 30 to $60 \mathrm{~min}$, with the mean duration $43 \mathrm{~min}$. Table 1 shows the demographics of the subjects. Mean age of the subjects was 41.6 years (range: 29 59 years), average years of experience as a nurse was 17 years (range: 6 - 28 years), and average years of experience in psychiatry was 13.5 years (range: 5 - 25 years).

\subsection{Analysis Results}

Concepts and categories involved in the study are described as follows: concepts, [ ]; categories, <>; and core categories, $<<>>$. Responses obtained from each subject in the interview are expressed in " ", and items that

Table 1. Demographics of the participants.

\begin{tabular}{|c|c|c|c|c|c|}
\hline ID & Age (years) & Sex & Years of nursing experience & $\begin{array}{l}\text { Years of nursing experience } \\
\text { in psychiatry }\end{array}$ & $\begin{array}{l}\text { Experience of studying } \\
\text { family nursing }\end{array}$ \\
\hline $\mathrm{Ns}^{\mathrm{a}} 1$ & $40 \mathrm{~s}$ & Male & 25 & 24 & No \\
\hline Ns 2 & $40 \mathrm{~s}$ & Female & 22 & 22 & Yes \\
\hline Ns 3 & $30 \mathrm{~s}$ & Male & 13 & 13 & No \\
\hline Ns 4 & $40 \mathrm{~s}$ & Male & 20 & 20 & Yes \\
\hline Ns 5 & $20 \mathrm{~s}$ & Female & 7 & 7 & No \\
\hline Ns 6 & $40 \mathrm{~s}$ & Female & 21 & 5 & No \\
\hline Ns 7 & $40 \mathrm{~s}$ & Male & 7 & 7 & No \\
\hline Ns 8 & $40 \mathrm{~s}$ & Female & 10 & 10 & No \\
\hline Ns 9 & $50 \mathrm{~s}$ & Female & 26 & 15 & No \\
\hline Ns 10 & $40 \mathrm{~s}$ & Female & 21 & 20 & No \\
\hline Ns 11 & $30 \mathrm{~s}$ & Male & 14 & 7 & No \\
\hline Ns 12 & $30 \mathrm{~s}$ & Male & 13 & 11 & No \\
\hline Ns 13 & $40 \mathrm{~s}$ & Male & 6 & 6 & Yes \\
\hline Ns 14 & $50 \mathrm{~s}$ & Female & 25 & 10 & No \\
\hline Ns 15 & $30 \mathrm{~s}$ & Male & 14 & 14 & No \\
\hline Ns 16 & $40 \mathrm{~s}$ & Female & 28 & 25 & Yes \\
\hline
\end{tabular}

a. Ns = Nurse. 
were both concepts and categories were expressed in $<[]>$. The author added notes in ( ) for content of comments that were hard to understand from the comment alone. ID numbers are the same as ones shown in Table 1. Results of the analysis identified 26 concepts, seven categories and one core category (Figure 1).

\subsection{Storyline}

Throughout the support process, support for families with BPD patients was provided based on $<<$ family support given without sufficient awareness of the nurses that they are supporting families $>>$. Nurses had an attitude to provide [the best support possible within the limited time and space], while at the same time having <perceptions that were premises for family support> that were shaped by past experiences in family support such as [being disappointed at a lack of understanding by the families] or individual nurses’ perspectives such as [Negativeness toward multidisciplinary cooperation]. Nurses recognized [families having difficulties in getting along with the patients] and [families with concerns due to prolonged hospitalization or uncertainty of the future] in providing care for BPD patients. Meanwhile, nurses have <perceptions of a diverse image of the families> such as [problematic (i.e. difficult to interact with) families], [families not capable of interacting with the patients effectively] and [families not seeking support proactively].

Nurses integrated < perceptions that were premises for family support> and <perceptions of animage of the family $>$ which in turn led to [determination and ambivalence about the need for family support]. When nurses recognized the need for support, $<$ [family support practice] $>$ was provided. During $<$ [family support practice] $>$, nurses experienced a [conflict between avoiding being involved too much and giving consideration to the feelings

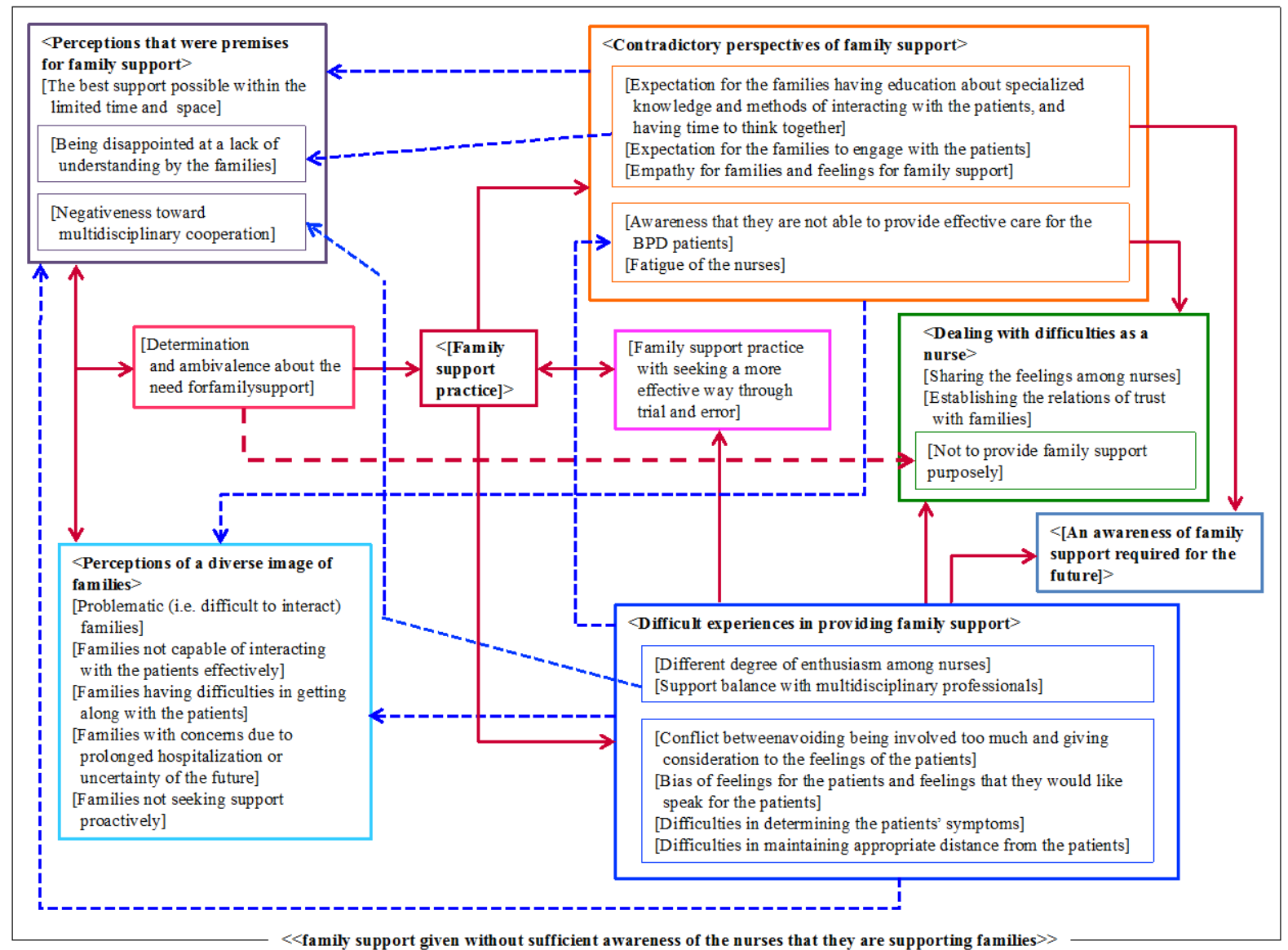

Figure 1. Process of support by nursing professionals for families having a member with a borderline personality disorder. Solid red lines: Arrows indicate the progression of the family support process, Broken red lines: Among the arrows indicating the progression of the family support process, arrows indicate consequences in which family support was not conducted, Broken blue lines: Arrows indicate the influences between concept and category. 
of the patients] due to [difficulties in determining the patients' symptoms], [difficulties in maintaining appropriate distance from the patients], and [bias of feelings for the patients, speaking for the patients]. They also had <difficult experiences in providing family support> which arose from care environment issues other than the family issues, such as [different degree of enthusiasm among nurses] or [support balance with multidisciplinary professionals]. When the family support did not go well due to < difficult experiences in providing family support>, they provided [family support practice with seeking a more effective way through trial and error]. When nurses did not find the need for support, they chose [not to provide family support purposely]. <Difficult experiences in providing family support> resulted in negative appraisal such as [fatigue of the nurses] or [awareness that they are not able to provide effective care for the BPD patients]. Meanwhile, nurses recognized the need for family support with [expectation for the families having education about specialized knowledge and methods of interacting with the patients, and having time to think together], [expectation for the families to engage with the patients], and [empathy for families and feelings for family support], resulted in having < contradictory perspectives of family support $>$. To deal with < contradictory perspectives of family support $>$ and $<$ difficult experiences in providing family support>, nurses took actions of <dealing with difficulties as a nurse>, such as [sharing the feelings among nurses], [to intentionally withhold family support], and [establishing the relations of trust with families] to maintain $<$ family support practice $>$. This process of family support ultimately led to $<$ an awareness of family support required for the future $>$. This was a cyclical process that $<$ contradictory perspectives of family support $>$ and $<$ difficult experiences in providing family support $>$ influenced $<$ perceptions that were premises for family support $>$ and $<$ perceptions of a diverse image of the families $>$.

\subsection{Details of Each Category and Developed Concept}

- $\quad<<$ Family support given without sufficient awareness of the nurses that they are supporting families $>>$

Definition: Situations that nurses interact with families without awareness that they are providing nursing intervention for families.

Ns.5 “As far as I know, there isn't much...well, I guess it (interaction between nurses and families) occurs sometimes when the doctor speaks at the time of hospitalization, or during hospitalization when families come to see the patients on occasion, nurses may talk to them, but I think it's very rare for the nurses to, you know, intervene in that."

Ns.6 "It's not in the form of 'family support,' the patient's mother, it's usually a mother accompanies the patient, sometimes I take plenty of time to listen to the mother, but it's not really in the form of support."

Ns.12 “Um, I don't know if I can say that I've been giving what I can call 'family support.' Hmm...I do believe that family support is necessary, though.”

Ns.13 "Mm, well, it's not exactly 'family support' as you'd find in a textbook, but really, I'm just a nurse with no authority, so, I don't really have so much experience speaking directly or approaching to the family form myself."

\subsubsection{Perceptions That Were Premises for Family Support}

Although nurses had an attitude to provide [the best support possible within the limited time and space], they also had <perceptions that were premises for family support> that were shaped by past experiences in family support such as [being disappointed at a lack of understanding by the families] or individual nurses' perspectives such as [negativeness toward multidisciplinary cooperation].

- $\quad$ [The best support possible within the limited time and space]

Definition: The nurse's recognition that they are providing family support within their job responsibilities, in the limited time frame and place.

Ns.1 "I respond to them when they come within the available range of time..."

Ns.4 "Yes, well, in the acute phase, it's hard to say just how much we can accomplish in a hospitalization period under 3 months...it's very hard, I think."

Ns.13 "Well, let's see...I have studied the ideal intervention or something, in the textbooks, so I'm aware that it's necessary, and it's always in the back of my mind to do it, but when it comes in my daily work, it was too hard to actually do it by according much weight to it."

Ns.7 "Well, I don't take a time especially for that; more often, I just speak to them when they come to visit the patient. So...I wonder, what can I do with it? I don't really have a sense of achievement...no." "Well, so I try my best to speak to them at least when they come to visit the patient, that's what I have been doing." 
- [Being disappointed at a lack of understanding by the families]

Definition: A feeling of sadness and imperfection as a nurse when the family blames health professionals with being involved in the patient's pathology, despite the nurses trying to relate to the family with empathy.

Ns.2 "Well, the lack of understanding of the illness may be part of it, but when the target of accusation is shifted from themselves (nurses) to the hospital, they (nurses) seem to feel a strong sense of relief, so there are some nurses who develop an inclination to blame the hospital.”

- [Negativeness toward multidisciplinary cooperation]

Definition: Circumstances of having insufficient awareness about multidisciplinary cooperation, or believing that it is better not to cooperate proactively.

Ns.2 "The psychologist is often involved in care for patients, but they don't become involved in care for families at all."

Ns.5 “Ah, well, as far as I'm aware, as well as primary doctors, the PSWs (= Psychiatric Social Workers) of the counselling division probably get involved in helping the patient finding a house or something. And for matters like insurance, etc., well, as far as I know, there aren’t any other professionals that get involved.”

Ns.14 "The doctors...well, hmm...let me think...well, it's with the doctors...the communication between doctors and nurses doesn't always go so well, so...”

\subsubsection{Perceptions of a Diverse Image of Families}

While being aware of families requiring family support, such as [families having difficulties in getting along with the patients] and [families with concerns due to prolonged hospitalization or uncertainty of the future], nurses also recognized that they wanted to maintain distance between themselves from some families, such as [problematic (i.e. difficult to interact) families]. In such cases, the nurses recognized their <perceptions of a diverse image of the family> who required no family support, such as [families not capable of interacting with the patients effectively] and [families not seeking support proactively].

- $\quad$ [Families having difficulties in getting along with the patients]

Definition: Families that have difficulties in dealing with the patient and have no idea what they can do.

Ns.3 “The patients, well, um, sometimes express what they want, but the family would not agree with them, and I think it's the biggest problem when they are in such a conflict.”

Ns.5 "I think families are really distressed by how to relate to the patients, and I think that makes them avoid the patients themselves."

- $\quad$ [Families with concerns due to prolonged hospitalization or uncertainty of the future]

Definition: Families that have concerns about the inability to visit frequently, being unable to respond to the patient's needs, a vague feeling of anxiety, or uncertainty of the future of the patients.

Ns.2 "Mm, it's usually all right for families who live close by, but families of patients who come to be hospitalized from far away are also traveling from far away to see them, so I feel that it can be a big burden for them as well.”

Ns.8 “...yes, I think so. I think they’re worried about their children's future, particularly about such young patients."

- [Problematic (i.e. difficult to interact) families]

Definition: Types of families in which nurse recognizes problematic (i.e. families that are difficult to interact with).

Ns.2 “And, they (families) often change their attitudes, don't they?”

Ns.4 "For the patients themselves it's normal, but for the family...well, they can have a role in the patients' development processes in various circumstances, for example, some families pampering the patients, or neglecting them..."

Ns.12 "Well, it's true that sometimes the parents are a little eccentric as well...and there were many families that didn't want their family matters to be pointed out...yes, there have been many cases like this. So they refuse to listen to us at all...”

- $\quad$ [Families not capable of interacting with the patients effectively]

Definition: Families showing unreasonable responses that can negatively affect the patients.

Ns.6 "When I hear from families that they withheld medication from the patient because the patient didn't eat a meal, I think that they really need to learn more about caring for the patient."

Ns.14 "Sometimes it's really frustrating. Sometimes I wish that they would listen a bit more to the patient, 
because the patient may become a little bit more relaxed then. But these families wouldn't listen much to the patient."

- $\quad$ [Families not seeking support proactively]

Definition: Families no seeking support proactively despite the apparent needs for support.

Ns.3 "Sometimes I notice families are in trouble, but they can't reveal it, and they're in trouble, they definitely are, but it seems like they are desensitized to such troubles, so, I try to speak to them in such cases."

Ns.15 "I think that a lot more families just muddle through at home by themselves."

\subsubsection{Determination and Ambivalence about the Need for Family Support}

Nurses integrated <perceptions of a diverse image of the families $>$ and <perceptions that were premises for family support $>$, and made judgements about needs for family support with [determination and ambivalence about the need for family support]. They also took their own experiences, abilities, and need for intervention as a nurse, into consideration.

Definition: Circumstances that nurses might find themselves in trouble judging the need for family support. An attitude of nurses that they link their judgements or circumstances of lack of proactive support to providing support.

Ns.12 "Well, I am a nurse, so I don't know for sure if I can intervene that much (as family support)..."

Ns.5 "I think it's different greatly depending on the age of the nurses or their level of experience. Nurses with more experiences may step in further, so sometimes I leave such intervention to senior nurses. A young nurse may not be convincing for the family...it might be just me, but if the family says, 'what do you know about this?' then there's nothing I can say, so when I need to say something important directly to the family, I ask experienced nurse to do it. That's what I do.”

\subsubsection{Family Support Practice}

When the need was determined through the process of $<$ [determination and ambivalence about the need for family support] $>$, nurses provided $<$ [family support practice] $>$. Various types of family support were provided, such as checking the situation when the inpatient spent time at home, providing information regarding to the patient, offering advice when families were in trouble with caring for the patient, or having multidisciplinary conferences. However, such support was provided as $<<$ family support given without sufficient awareness of the nurses that they are supporting families $>>$.

Definition: Family care provided by nurses

Ns.2 "Well, for patients who have been diagnosed as well, but in most cases the doctors, um, meet the family in the form of disease education as a part of family education... also when setting boundaries (limits), nurses also accompany, like nurse participation in education, and that is one of the ways we provide support.

Ns.4 "I think so, we make clear what we can do or cannot do, otherwise families would be confused."

Ns.8 "In general, when they come to pick the patient up to spend time outside or for spending a night away, I speak to the families a little bit, and that's when I inform them what the patient's life in the ward is like, like a report...."

Ns.11 "Well, I don’t provide any specific family support, but in terms of support that I can provide, well, I listen to them, as I assume that families have experienced difficulties. So, I listen to the families' stories carefully and even for just a short period, at least during the hospitalization, families can take some break time. I think it can be a kind of support for them.”

Ns.16 "It's just observing the circumstances. And listening to their problems, what to do in a certain situation, or listen to their complaints and so on."

\subsubsection{Difficult Experiences in Providing Family Support}

Nurses had <difficult experiences in providing family support $>$ through $<$ [family support practice] $>$. The experiences included difficulties in nursing derived from the patient's disorders such as [difficulties in determining the patients' symptoms], [difficulties in maintaining appropriate distance from the patients], and [conflict between preventing being involved and giving consideration to the feelings of the patients]. Through interactions with the patients and families, nurses experienced [bias of feelings for the patients and feelings that they would like to speak for the patients] and [having a realization that family environment and symptom control closely relate each other]. Nurses also experienced difficulties due to circumstances other than families, such as [different 
degree of enthusiasm among nurses] and [support balance with multidisciplinary professionals].

- [Difficulties in determining the patients' symptoms]

Definition: Difficulties experienced in considering to what extent nurses should help, with not knowing if specific behaviors of the patients are due to their characters or symptoms of their disorder.

Ns.7 “Well, you know, you can't just read books to understand this illness. You have to hear it from people who have experienced it a lot. Then you may understand, like, well, it's because of family environment, something like this."

- [Difficulties in maintaining appropriate distance from the patients]

Definition: Difficulties arising between psychological distances that is to construct a relationship of trust with the patient and that is to prevent codependence.

Ns.7 "Yes, that's true. When we keep too much distance, they will think we are not caring for them, but if I get too close, you know...(laugh), sometimes they bring in love letters."

Ns.15 "A little close, but not too close. If you get too close, in the worst case, they may behave violently, so you can't get too close. The determination of distance is difficult, isn't it."

- [Conflict between preventing being involved and giving consideration to the feelings of the patients]

Definition: Circumstances that nurses recognizes the need for interaction being involved in the patients while paying attention not to be involved in the patients' disorders.

Ns.4 "Like being involved, well, it may be unavoidable, though."

Ns.6 "I try not to get involved, but sometimes I get frustrated, well. It's so hard not to be involved."

- [Bias of feelings for the patients and feelings that they would like speak for the patients]

Definition: Nurses' experiences of feelings in which they empathize with the patients and would like to speak for the patients.

Ns.5 "I guess that's one of the roles of the nurse to protect the patient in that way, and I believe there's something that we can say to the family in that sense."

Ns.14 "Arrangement...So that the patient can live a calm, relaxed life."

- $\quad$ [Different degree of enthusiasm among nurses]

Definition: Inadequate information sharing among nurses regarding their perspectives of the families and nursing practice they performed.

Ns.3 "Well, I don't know, to what extent other nurses provide care, I think it depends on each nurse, so I have never shared it with others."

Ns.8: "Some nurses may engage in the support, but I don't, because I don't think it's necessary. Nurses who want to, they can do, but there is not any point pushing ourselves."

- [Support balance with multidisciplinary professionals]

Definition: Nursing experiences in which nurses try not to overplay according to therapeutic measures of the physicians and integrated nursing practice.

Ns.5 “Well, how can I say, I don't think we offer that kind of support very much in this facility. Doctors do it, and we follow what the doctors set as boundaries (limits)."

Ns.7 "Well you know, like having our nose in...it's hard to put our nose in."

- $\quad$ [Family support practice with seeking a more effective way through trial and error]

Definition: Family support that individual nurses provide in their own sense of requirement, as they are unable to respond to diversity of the families.

Ns.11 "Yes, I do say it. At least once a month, I ask families to come see the patient. Well, no particular procedure, but just my own line."

Ns.15 "Well...it's like a trick, it’s like what I feel like."

Ns.16 "Really, by trial-and-error."

- $\quad$ [To intentionally refrain from family support]

Definition: Attitude not to provide proactive support to avoid placing additional burden on families and nurses

Ns.8 “I don't see families seeking support, so why do we have to? I don't."

Ns.9 “Is BPD an illness? Sometimes I can't help feeling like it's nothing but simply selfishness. I can’t play along with their selfishness, and that's also the wish of the family. It doesn't work even if I try to get involved, so I don't think it's necessary.”

\subsubsection{Contradictory Perspectives of Family Support}

There were conflicts between negative feelings toward family support (i.e. [fatigue of the nurses] and [aware- 
ness that they are not able to provide effective care for the BPD patients]), and awareness of the needs for support (i.e. [expectation for the families having education about specialized knowledge and methods of interacting with the patients, and having time to think together], [expectation for the families to engage with the patients], and [empathy for families and feelings for family support]).

- $\quad$ [Fatigue of the nurses]

Definition: Fatigue of the nurses arising from difficulties in interactions with BPD patients and their families.

Ns.6 "Families often bitterly complain with an aggressive manner. So, if the nurse is like the one who can talk straight in the nurses' station, she'd be fine. But if the one like swallows her emotion over, she may become overwhelmed."

Ns.16 “Hmm, it's tough. Its' very tough for me."

- [Awareness that they are not able to provide effective care for the BPD patients]

Definition: Nurses' awareness of their incapability caused by characteristics of BPD

Ns.1 "Like being pushed around or disturbed, you know, it’s hard to have a good impression of the patients, I know it sounds really bad." "No, in fact, I admit I have a hard time with them."

Ns.13 "I am bad at caring for them...Well, I don't like doing so very much. Because I've had quite hard experiences with them."

- $\quad$ [Expectation for the families having education about specialized knowledge and methods of interacting with the patients, and having time to think together]

Definition: Expectation that education of specialized knowledge and methods of interaction, and having time to think together can help families facing the patients.

Ns.2 "Well, I expect understanding of the disorder, and when there's something, like the patient attempted suicide or such episodes, I hope families can face the patient without becoming upset. They usually get very upset."

- [Expectation for the families to engage with the patients]

Definition: Hopes for families being able to face the patient genuinely, rather than solely making successful responses.

Ns.2 "Response, well, becoming a family being able to face the patient is my expectation."

Ns.11 "Instead, when the patient is discharged, you know, families are required to face the patient again."

- [To intentionally refrain from family support] [Empathy for families and feelings for family support]

Definition: Circumstances that nurses feel the need for support through recognizing and understanding difficulties the families face.

Ns.3 "Often families are desensitized, or they cannot express their needs, they have such aspects, which requires some intervention, I guess...I want to reduce their burden, and I think reducing families' burden would have a positive influence on the patients, so I'd like to do so."

\subsubsection{Dealing with Difficulties as a Nurse}

Having been through <contradictory perspectives of family support> and < difficult experiences in providing family support>, nurses attempted to cope with their own stress by [sharing the feelings among nurses]. They also attempted [establishing the relations of trust with families] to promote better family support. In some cases, they decided [not to provide family support purposely].

- $\quad$ [Sharing the feelings among nurses]

Definition: Circumstances that common understanding and share of feelings can be moral support for nurses

Ns.2 "Well, I really value sharing such feelings between staff...I think it's the most important thing."

- $\quad$ [Establishing the relations of trust with families]

Definition: One of the methods to lay out the circumstances for providing family support

Ns.12 "Yes. I tried this (=establishing relationship), after taking a break for a certain period, when I felt that building human relationship with families was becoming possible, or when I was asked for advice at the right moment."

\subsubsection{An Awareness of Family Support Required for the Future}

The ultimate consequences led to nurses' awareness of family support for the future, and it influenced their $<$ perceptions that were premises for family support> and <perceptions of diverse images of the families $>$. 


\section{Discussion}

This study illustrated the process of family support that nurses provided for families with BPD patients. This was a comprehensive process based on "family support given without sufficient nurses' awareness of the nurses that they are supporting families.” In Japan, it is generally recognized is providing care to BPD patients is difficult, and supporting the families of such patients even more challenging. The first step in establishing family support may be a modification of the circumstances in which nurses are not aware that supporting families is also part of their daily practices. Such circumstances are also observed in other care domains with fewer opportunities to interact with families of patients. However in this study, nurses recognized that they are not providing any support, irrespective of the fact that they felt the need for family support through the care process of the patients. Such a false perception may lead to the nurses' sense of inadequacy, and undermine their motivation to subsequently provide family support. Nursing practice is one form of human caring [12], and so is family support. Considering Caritas' ten concepts of caring, such as instilling of faith-hope, development of a helpingtrusting, human care relationship, and promotion of transpersonal teaching-learning, inadequate awareness of practicing represents a serious detachment from establishing effective care, with negligible achievement of these concepts.

Determination of need for support, which is based on the presumption of family support and an image of families, directly leads to the family support practice. To facilitate this process, reducing negative factors that can affect the need for family support derived from perceptions for premise, and enhancing an awareness of the need for family support through "perceptions of the image of the family," Are required. As "perceptions of an image of the family" show different images of families such as needing, or not needing care, some cases resulted in the intentional withholding of family support. However, insufficient support services in the community and need for such services have been demonstrated by previous studies. Providers of such support services need education and training for behavioral modification to avoid discrimination, recognize the service recipients' needs, and provide more effective support [13]. By first understanding the circumstances of the families, such as being unable, for example, to disclose their concerns due to a fear of health professionals' negative bias, may lead in turn to meaningful family support. Recent studies indicated that inadequate mother-child interactions could aggravate the transmission of borderline symptoms from mother to child [14], which has been observed in problematic (i.e. difficult to interact) families. Therefore, the difficulties in interactions can be seen not only with the patients but also families, resulting in greater challenges to family support than nursing practice focused merely on patients.

In the course of providing family support, difficulties arising among nurses or multidisciplinary professionals, and the patients' disorders, can be exhausting for nurses. The results of this current study suggested that nurses were able to maintain themselves carrying on with their nursing practice by dealing with difficulties as part of the nursing profession. Therefore, change and arrangements of family environment to facilitate implementation of support service are also required [15]. Although perspectives on the management side regarding education and training for nurses were not mentioned in the current study, their enhancement will also be urgent issues. Furthermore, as difficult experiences in providing family support can be factors impeding the family support process, reducing differences in degrees of enthusiasm among nurses and keeping a balance in support with multidisciplinary professionals may facilitate the support process. Recently, multidisciplinary cooperation has been actively promoted in patient support services such as discharge support. However, according to the results of this study, care for the BPD patients revolved mainly around treatment strategies of psychiatrists, and nurses were engaging in the care with careful attention not to overstep the boundaries of their position. In Japan, the Ministry of Health, Welfare and Labour has been promoting team medicine [16] since 2010. Each discipline of professions are expected to fulfill their respective roles by providing support accordingly. Transforming difficulties in the multidisciplinary approach into advantages will be required for providing more effective family support.

\section{Conclusion}

In this study, 16 nursing professionals having experience in caring for families with a BPD patient were the subjects of semi-structured interviews, thereby clarifying the family support process being provided to such family members. Twenty-six concepts, seven categories and one core category were extracted. At the basis of factors that impeded progress in the family support process was $<<$ Family support given without sufficient awareness of the nurses that they are supporting families $>>$, making the implementation of $<$ [Family support 
practice] $>$ the most important consideration in their nursing practice. Furthermore, $<$ [Determination and ambivalence about the need for family support] $>$ was found to play a direct influence on $<$ [Family support practice] $>$, and determining the importance of the two stages of $<$ Perceptions that were premises for family support $>$ and $<$ Perceptions of (a diverse image of) families $>$, may be a precondition for providing such support. However, $<$ Contradictory perspectives of family support $>$ and $<$ Difficult experiences in providing family support $>$ influence these, and appear to result in discouraging nursing professionals from taking a more active role in family intervention. By attaching affirmative meanings to these categories, and by further augmentation of $<$ Dealing with difficulties as a nurse>, it is believed that the family support process to members of families with a BPD patient will be further advanced. Moreover, through the favorable progression of this process, it is believed that cases in which family support is not currently being intentionally provided will be implemented, thereby bringing about quality of life improvements in families with BPD patients.

\section{Acknowledgements}

The authors in particular wish to acknowledge the contributions of nurses who took part in the study. This thesis was submitted to the Graduate School of Health Sciences, Kobe University in partial fulfillment of the requirements for a doctoral degree for the first author.

\section{Declaration of Conflicting Interests}

The authors declare that they have no competing interests.

\section{References}

[1] American Psychiatric Association (2013) Diagnostic and Statistical Manual of Mental Disorders: DSM-5. 5th Edition. American Psychiatric Association, Washington DC.

[2] Zweig-Frank, H. and Paris, J. (1991) Parents Emotional Neglect and Overprotection According to the Recollections of Patients with Borderline Personality Disorder. American Journal of Psychiatry, 148, 648-651. http://dx.doi.org/10.1176/ajp.148.5.648

[3] Bezirganian, S., Cohen, P. and Brook J.S. (1993) The Impact of Mother-Child Interaction on the Development of Borderline Personality Disorder. American Journal of Psychiatry, 150, 1836-1842. http://dx.doi.org/10.1176/ajp.150.12.1836

[4] Glick, I.D., Dulit, R.A., Wachter, E. and Clarkin, J.F. (1995) The Family, Family Therapy, and Borderline Personality Disorder. Journal of Psychotherapy Practice and Research, 4, 237-246.

[5] Grant, B.F., Chou, S.P., Goldstein, R.B., Huang, B., Stinson, F.S., Saha, T.D., et al. (2008) Prevalence, Correlates, Disability, and Comorbidity of DSM-IV Borderline Personality Disorder: Results from the Wave 2 National Epidemiologic Survey on Alcohol and Related Conditions. Journal of Clinical Psychiatry, 69, 533-545. http://dx.doi.org/10.4088/JCP.v69n0404

[6] Coid, J. (2003) Epidemiology, Public Health and the Problem of Personality Disorder. British Journal of Psychiatry, 182, s3-s10.

[7] Ushijima, S. (2008) Japanese Version of Treatment Guidelines for Borderline Personality Disorder. Japanese Nursing Association Publishing Company, Tokyo.

[8] Shirahase, J. (2010) From Special Diseases to Ordinary Diseases. Human Mind, 154, 12-18.

[9] Sudo, A. (2006) The Process by Which Nurses Develop the Idea That Borderline Personality Disorder Patients Are Difficult to Care for. Bulletin of Niigata Seiryo University, 6, 141-150.

[10] Kinoshita, Y. (2003) Practice of Grounded Theory Approach. Koubundou Publishers, Tokyo.

[11] Glaser, B.G. and Strauss, A.L. (1967) Discovery of Grounded Theory: Strategies for Qualitative Research. Aldine De Gruyter, New York.

[12] Watson, J. (1999) Nursing: Human Science and Human Care: A Theory of Nursing. Jones \& Bartlett, Sudbury.

[13] Lawn, S. and McMahon, J. (2015) Experiences of Family Carers of People Diagnosed with Borderline Personality Disorder. Journal of Psychiatric Mental Health and Nursing, 22, 234-243. http://dx.doi.org/10.1111/jpm.12193

[14] Reinelt, E., Stopsack, M., Aldinger, M., Ulrich, I., Grabe, H.J. and Barnow, S. (2013) Longitudinal Transmission Pathways of Borderline Personality Disorder Symptoms: From Mother to Child? Psychopathology, 47, 10-16. http://dx.doi.org/10.1159/000345857 
[15] Ministry of Health, Labour and Welfare (2010) Report of the Consideration Group for the Promotion of Team Treatment. http://www.mhlw.go.jp/shingi/2010/03/dl/s0319-9a.pdf

[16] Hohashi, N. and Honda, J. (2011) Development of the Concentric Sphere Family Environment Model and Companion Tools for Culturally Congruent Family Assessment. Journal of Transcultural Nursing, 22, 350-361.

http://dx.doi.org/10.1177/1043659611414200

\section{List of Abbreviations}

BPD: borderline personality disorder

M-GTA: modified grounded theory approach

GTA: grounded theory approach

Ns: nurse

PSWs: psychiatric social workers 